\title{
Bacterial profile and antibacterial susceptibility of otitis media among pediatric patients in Hawassa, Southern Ethiopia: cross-sectional study
}

Bereket Tadesse ${ }^{1}$, Techalew Shimelis ${ }^{2}$ and Mesfin Worku ${ }^{3 *}$

\begin{abstract}
Background: Otitis Media (OM) is the most common disease of childhood. Twenty thousand people die each year from otitis media. It is an important cause of preventable hearing loss, affects children's intellectual performance and language development. There are very small numbers of studies done in Ethiopia concerning this topic. This study aimed to identify bacterial pathogens related to ear infection and to assess antibacterial susceptibility of isolated organisms.
\end{abstract}

Method: A cross-sectional study was conducted on 152 children from April 2018 to July 2018 at selected health facilities in Hawassa city, SNNPR, Ethiopia. All pediatric patients having ear discharge were included. Convenient sampling technique was used to collect clinical and demographic data using standard questionnaires after child care-takers signed the consent. Ear discharge specimens were collected using a sterile swab, and transported using Amies transport media to Hawassa University Comprehensive Specialized Hospital laboratory. Bacterial isolates were characterized based on colony appearance, Gram reaction, culture characteristics, and biochemical tests after inoculating on appropriate culture media. Antibacterial susceptibility testing was performed using the disc diffusion method according to the criteria of the Clinical and Laboratory Standards Institute (CLSI).

Results: Among 152 children included, 115(75.6\%) of them demonstrated pathogenic bacterial growth. Staphylococcus aureus 41(27\%) was the most frequently isolated pathogen, followed by Proteus mirabilis 19 (12.5\%). Of the total isolates, 11.2 and $7.3 \%$ were resistant to gentamicin and ciprofloxacin respectively. Over three-fourth (85.2\%) of the isolates were resistant to ampicillin. More than two-third of the isolates were resistant to both penicillin (71.4\%) and trimethoprim-sulphamethoxazole (72.0\%).

Conclusions: $S$. aureus is the most commonly isolated bacterial pathogen from ear discharge among children. Even though gentamicin is a parenteral drug and ciprofloxacin is rarely used in children due to concerns of bone/joint effects, these two drugs were highly effective antibiotics and thus should be considered in treating children with otitis media since most organisms were resistance or poor response to first line drugsHigh level of antibiotic resistance was observed so antimicrobial susceptibility test is needed before prescribing drugs for treatment of OM.

Keywords: Paediatric ear infection, Bacterial isolates, Antibiotic resistance

\footnotetext{
* Correspondence: mesfinwh@gmail.com

${ }^{3}$ College of Medicine and Health Science, School of Medical Laboratory,

Hawassa university, Hawassa, Ethiopia

Full list of author information is available at the end of the article
}

(c) The Author(s). 2019 Open Access This article is distributed under the terms of the Creative Commons Attribution 4.0 International License (http://creativecommons.org/licenses/by/4.0/), which permits unrestricted use, distribution, and reproduction in any medium, provided you give appropriate credit to the original author(s) and the source, provide a link to the Creative Commons license, and indicate if changes were made. The Creative Commons Public Domain Dedication waiver (http://creativecommons.org/publicdomain/zero/1.0/) applies to the data made available in this article, unless otherwise stated. 


\section{Background}

Otitis Media is the most common disease of childhood, with about 65-330 million people suffering from ear infection worldwide and $60 \%$ of them have significant hearing impairment [1]. It is estimated that 20,000 people die each year from otitis media and the overall burden of these diseases is higher in the poorest countries [2]. The health-economic burden of ear infection is also severe especially in Africa and other developing nations where the disease prevalence is estimated as high as $11 \%$ [3].

Complications of Otitis Media (OM) such as perforation of the tympanic membrane, otitis externa and mastoiditis affect balance, motor control and hearing. Acquired hearing impairment in children is mainly caused by chronic suppurative otitis media (CSOM). The hearing impairment produced by otitis media also affect intellectual performance and language development $[4,5]$.

The growing bacterial resistance to antibiotics has altered the clinical picture of otitis media and its complications. The emergence of Multi Drug Resistance (MDR) is clearly related to the dose of antibiotics and how they are being used [6]. Serious infections caused by methicillin-resistant $S$. aureus (MRSA) are increasingly difficult to treat. While it is clear that antibiotics are pivotal in the selection of bacterial resistance, the spread of resistance genes and resistant bacteria also contributes to the problem [7]. Most of the time treatment for OM is done clinically, especially in health facilities found in low income countries. This will cause bacterial drug resistance and preventable complications of OM such as deafness and meningitis [8] .

There are a small number of studies done in Ethiopia concerning this topic, moreover, almost all of them show the emergence of these drug resistant bacterial strains and recommend further study [9] . Therefore this study aimed to identify bacterial pathogens related to ear infection and to assess antibacterial resistance among isolated organisms.

\section{Methods}

\section{Description of the study area and period}

Hawassa is the capital of the Southern Nations, Nationalities and People's Region and is located $275 \mathrm{~km}$ from Addis Ababa, the capital city of Ethiopia. The study was conducted in the Hawasa University Comprehensive Specialized Hospital, Adare Hospital, Tilte Health Centre and Rama Paediatric Clinic. Those sites are selected based on reports of higher rates of otitis media in children (personal communication with health facilities and by reviewing the 6 month report). This facility based cross- sectional study was conducted from April 2018 to July 2018.

\section{Sample size}

A total of 152 study participants were included using single population proportion formula based on estimated prevalence (p) taken from Yitayal S. et al. in 2013 which was $90 \%$ in pediatric patients, margin of error (5\%), $95 \%$ confidence level CI ( $\mathrm{z}=1.96)$.

\section{Data collection \\ Demographic characteristics and risk factors}

Data on socio-demography and potential risk factors were collected using a questionnaire developed for this study. Data collectors (a translator as necessary) approached children with ear discharge at the outpatient department of the study sites and provided information for the parents or care-takers regarding the study. After allowing them to think and discuss and attending all questions, they were asked to sign the informed consent. Those patients whose care takers signed the written consent were interviewed by health officers or a physician. All paediatric patients under the age of 15 years with ear discharge were included whereas children on antibiotic treatment in last 2 weeks were excluded.

\section{Specimen collection, transport and processing}

Ear discharge specimens were collected at collection sites aseptically by an ENT Specialist or health officers using a sterile cotton swabs after the patient's ear was washed by normal saline $(0.85 \% \mathrm{NaCl})$. Samples were kept in Amies transport media to maintain the viability of microorganisms until the specimen is processed. And specimens were transported for processing within $2 \mathrm{~h}$ to Microbiology laboratory of Hawassa University Comprehensive Specialize Hospital (HUCSH).

\section{Sample processing and culturing}

All ear discharge specimens were inoculated on blood agar, chocolate agar, and MacConkey agar. All inoculated agar plates were incubated at aerobic atmosphere whereas chocolate agar was incubated in carbon dioxide enriched atmosphere using a candle jar to enhance the growth of S. pneumoniae at $37^{\circ} \mathrm{C}$ for $24-48 \mathrm{~h}$ [10] . Preliminary identification of all positive cultures was done based on observation of growth on primary culture media and examination of Gram-staining reaction under microscope.

\section{Characterization of isolated bacteria}

Bacterial isolates were characterized based on colony appearance, gram reaction, culture characteristics, and biochemical tests as described by Cheesbrough. Biochemical tests carried out include: catalase, urease, coagulase, oxidase, carbohydrate fermentation, motility, gas production, $\mathrm{H}_{2} \mathrm{~S}$ production, citrate utilization, and Indole test. Satellitism test and XV factor tests was done 
for identification of $H$. influenza. Identification of $S$. pneumonae and Entrococcus spp was done using Optochin disc test [10]. Identification of MRSA was done using cefoxitin disc diffusion method and MLSBi was identified by performing the D test. Staphylococcus aureus isolates showing circular zones of inhibition with diameter of $\leq 13 \mathrm{~mm}$ for ERY and $\geq 21 \mathrm{~mm}$ for CLN without a D-shaped zone along the ERY were interpreted as negative for inducible resistance (D-test negative). $S$. aureus isolates with same inhibitory diameters as above with a D-shaped zone around the CLN were interpreted as positive for inducible resistance (D-test positive) [11].

\section{Antibacterial susceptibility testing}

Antibacterial susceptibility testing was performed by disc diffusion method for all isolates according to the criteria of the Clinical and Laboratory Standards Institute (CLSI) version 2017. From a pure culture 3-5 selected colonies of bacteria were taken and transferred to a tube containing 5 â€\%oml nutrient broth and mixed gently until a homogenous suspension was formed and incubated at $37^{\circ} \mathrm{C}$ until the turbidity of the suspension become adjusted to a McFarland 0.5. A sterile cotton swab was used and the excess suspension was removed by gentile rotation of the swab against the internal surface of the tube. The swab was then used to distribute the bacteria evenly over the entire surface of Mullen Hinton agar. The inoculated plates were left at room temperature to dry for 3 to $5 \hat{a} € \%$ min and a set of antibiotic discs such as ampicilin $(10 \mathrm{~g})$, ciprofloxacilin $(5 \mu \mathrm{g})$, gentamicin $(10 \mu \mathrm{g})$, ceftriaxone, penicilin G $(10 \mu \mathrm{g})$, cefoxitin, amoxicillin-clavulonate $(30 \mu \mathrm{g})$, chloroamphenicol, and tetracycline $(30 \mu \mathrm{g})$ were dispensed on the surface of the inoculated Muller-Hinton plate. All drugs were selected based on recommendation of CLSI guidelines (2017 version). For fastidious organisms, a chocolate agar plate (for $H$. infuenzae) and modified Muller-Hinton agar (for S. pneumoniae) were used. The inoculated plate was incubated at $37^{\circ} \mathrm{C}$ for $18-24 \mathrm{~h}$ [11].

\section{Data management and quality control}

The questionnaire was first prepared in English and was translated into Amharic and back translated into English by another person to check its consistency. Before the actual data collection time, the questionnaire was pretested using 26 volunteers (5\% of the sample), in Hawassa University's Comprehensive Specialized Hospital to check for any missing options, ambiguity and clarity. Data quality was ensured through use of standardized data collection materials. Proper training was given for data collectors before the start of data collection and intensive supervision was done during data collection by the principal investigator.

For laboratory analysis pre-analytical, analytical and post-analytical stages of quality assurance in standard operating procedures (SOPs) of the microbiology laboratory were strictly followed. In addition, well-trained and experienced laboratory professionals participated in the laboratory analysis procedure. Quality control strains such as E. coli (ATCC-25922), S. aureus (ATCC-25923) and $P$. aeruginosa (ATCC-27853) were included from the Armauer Hansen research institute (AHRI) to check all media and biochemical tests and sensitivity. Performance tests were also conducted on 5\% of prepared media.

\section{Data analysis}

Data collected with questionnaires and laboratory investigations were entered and analyzed using SPSS version 20 (IBM Corp. Released 2011. IBM SPSS Statistics for Windows, Version 20.0. Armonk, NY: IBM Corp.). Study findings were presented in words and tables. Frequencies and proportions were used to summarize sociodemographic and other factors. Multivariable logistic regression analysis was performed taking those sociodemographic and risk factors found to be significantly associated with bacterial ear infection in bivariate logistic regression analysis. Associations between dependent and independent variables were assessed and strength was described using odds ratios and 95\% confidence intervals. $P$-values less than 0.05 were interpreted as statistically significant.

\section{Results \\ Description of socio demographic characteristics}

A total of 152 children with ear discharge were included in this study from April 2018 to July 2018. Among these, $78 / 152(51.3 \%)$ were males. The age range of participants was from 3months to 12years, with a mean age of 2.59 years. Nearly half of participants $80 / 152$ (52.6\%) were in the age group of 1 to 4years, and the majority of the study subjects 105 (69.5\%) were urban residents [Table 1].

\section{Culture results}

Among 152 individuals whose samples were cultured, at least one pathogenic bacterial isolate were detected in $115 / 152$ (75.7\%). A total of 123 bacterial isolates were detected; of which 59/123 (48.0\%) were Gram positive and 64 (52.0\%) were Gram negative bacteria. Eight samples had two different types of bacterial isolates.

Staphylococcus aureus 41/152 (27.0\%) was the most frequently isolated pathogen followed by $P$. mirabilis $19 /$ 152 (12.5\%), Haemophilus influenzae 14/152 (9.2\%), E. coli 11/152 (7.2\%), Enterococcus species 10/152 (6.6\%), Streptococcus pneumoniae 8/152 (5.3\%), Klebsiella pneumoniae 6/152 (3.9\%), and Klebsiella ozeanae 6/152 (3.9\%). The majority of the bacterial isolates $99 / 152$ 
Table 1 Socio demographic characteristics of children with ear discharge, Hawassa, SNNPR, April to July, 2018

\begin{tabular}{llll}
\hline Variables & & Number & Percent \\
\hline Sex & Male & 78 & 51.3 \\
Age (in years) & Female & 74 & 48.7 \\
& $<1$ & 48 & 31.6 \\
& $1-4$ & 80 & 52.6 \\
& $5-10$ & 21 & 13.8 \\
Residence & $11-15$ & 3 & 2.0 \\
& Urban & 105 & 69.5 \\
Place of stay & Rural & 47 & 30.9 \\
in day time & Home & 118 & 77.8 \\
& School & 32 & 21.1 \\
& Day care & 2 & 1.3 \\
\hline
\end{tabular}

(65.1\%) were found in children less than 5 years of age [Table 2].

Twelve out of $14 H$. influenza isolates were identified from the children less than $12 \hat{a} € \%$ months of age. On the other hand, out of total 19 P. mirabilis isolates, 16/ $19(84.2 \%)$ were identified from children aged between 1 and 5 years. Moreover, S. aureus had higher frequency in all age groups. The frequency of Pseudomonas species was only $4(2.6 \%)$.

\section{Drug resistance patterns}

E. coli (36.4\%) and Enterococcus species (50.0\%)showed resistance to ciprofloxacin but the rest of all isolated Gram positive and Gram negative bacteria showed no (0.0\%) resistance to ciprofloxacin. On the other hand, all Gram negative bacteria except $P$. mirabilis (68.4\%) were $100 \%$ resistant to ampicilin. $11.2 \%$ of pathogens showed resistance to gentamycin but only $K$. pneumonia was $100 \%$ resistant. Klebsiella species showed higher resistance for most of the antimicrobials tested, but isolates were susceptible to ciprofloxacin [Table. 3].

S. pneumonia showed no resistance for any of the drugs tested. $S$. aureus showed higher resistance to penicillin (85.4\%) and trimethoprim-sulphamethoxazole (73.2\%). However, all isolates of $S$. aureus were susceptible to ciprofloxacin and gentamycin. Only half of the isolated Enterococcus species were susceptible to both ciprofloxacin and erythromycin. All Enterococcus species are susceptible to chloraphenicol [Table.4].

Regarding drug resistance rates, 85.2, 72.0 and $71.4 \%$ of the isolated bacteria were resistant to ampicilin, trimethoprim-sulphamethoxazole and penicillin respectively. These were followed by 37.5, 31.3, 22.6 and $11.2 \%$ of the isolates resistant to ceftriaxone, ceftazidime, chloramphenicol and gentamicin respectively. Only 7.3\% of the isolates were resistant to ciprofloxacin.

From the total (41) isolated S. aureus, 6 (14.6\%) showed erythromycin induced clindamycin resistance also known as MLSBi resistance which is observed as a â $€^{\sim} \mathrm{Dâ} €^{\mathrm{TM}}$ shape on Muller Hinton agar and $7(17.0 \%)$ of them were methicilin resistant S. aureus (MRSA). Out of the seven MRSA identified, 2(28.5\%) of them showed erythromycin-inducible clindamycin resistance.

\section{Description of potential risk factors}

From the 152 study subjects 52(34.4\%) of them had an ear infection longer than 2 weeks and 57 (37.5\%) of the participants had a history of taking antibiotics. Eighty six (56.6\%) of the children included in this study were breast feeding and 56 (36.8\%) of the children were fed by bottles. Upper respiratory tract infection, including throat

Table 2 Bacterial isolates among age groups of study participant with ear infection visiting selected health facilities in Hawasa, Ethiopia, April 2018 July 2018

\begin{tabular}{|c|c|c|c|c|}
\hline \multirow[t]{2}{*}{ Isolated organism } & \multicolumn{3}{|c|}{ Age group of the study participant } & \multirow{2}{*}{$\begin{array}{l}\text { Total } \\
(n=152)\end{array}$} \\
\hline & $<1$ year $(n=48)$ & 1 years $(n=80)$ & $6-12$ years $(n=24)$ & \\
\hline S. aureus & 14 & 17 & 10 & $41(27 \%)$ \\
\hline P. mirabilis & 1 & 16 & 2 & $19(12.5 \%)$ \\
\hline H. influenzae & 12 & 2 & 0 & $14(9.2 \%)$ \\
\hline E. coli & 5 & 6 & 0 & $11(7.2 \%)$ \\
\hline Enterococcus species & 4 & 4 & 2 & $10(6.6 \%)$ \\
\hline S. pneumoniae & 6 & 2 & 0 & $8(5.3 \%)$ \\
\hline K.pneumoniae & 0 & 6 & 0 & $6(3.9 \%)$ \\
\hline K. ozienae & 0 & 6 & 0 & $6(3.9 \%)$ \\
\hline Pseudomonas species & 1 & 3 & 0 & $4(2.6 \%)$ \\
\hline Providenica species & 0 & 0 & 2 & $2(1.3 \%)$ \\
\hline Acinetobacter species. & 0 & 2 & 0 & $2(1.3 \%)$ \\
\hline Total & 37 (24.3\%) & $62(40.8)$ & $16(10.5)$ & 152 (100\%) \\
\hline
\end{tabular}

$n$ number of participant 
Table 3 Antimicrobial resistance patterns of Gram-negative bacteria isolated from ear infection among children visiting selected health facilities, Hawassa, Ethiopia, 2018

\begin{tabular}{|c|c|c|c|c|c|c|c|c|c|c|}
\hline Isolated organisms & AMP & $\mathrm{CIP}$ & SXT & GEN & AUG & CTR & CAZ & MER & $\mathrm{CHL}$ & TET \\
\hline P.mirabilis & $68.4 \%$ & $0.0 \%$ & $57.9 \%$ & $10.5 \%$ & $57.9 \%$ & $10.5 \%$ & $10.5 \%$ & $21.1 \%$ & $31.6 \%$ & ND \\
\hline E.coli & $100 \%$ & 36.4 & $72.7 \%$ & $18.2 \%$ & $81.8 \%$ & $18.2 \%$ & $18.2 \%$ & $0.0 \%$ & $18.2 \%$ & ND \\
\hline H.influenza & $100 \%$ & $0.0 \%$ & $16.7 \%$ & ND & $50 \%$ & $50 \%$ & $66.7 \%$ & $100 \%$ & $0.0 \%$ & ND \\
\hline K.oziena & $100 \%$ & $0.0 \%$ & $66.7 \%$ & 33.3 & $66.7 \%$ & $33.3 \%$ & 33.3 & $33.3 \%$ & $33.3 \%$ & $33.3 \%$ \\
\hline K.pneumonia & $100 \%$ & $0.0 \%$ & $100 \%$ & $100 \%$ & $66.7 \%$ & $100 \%$ & 66.7 & $33.3 \%$ & $66.7 \%$ & $66.7 \%$ \\
\hline Pseudomonas.spp. & ND & $0.0 \%$ & ND & 25 & ND & $100 \%$ & 25 & $25.0 \%$ & ND & ND \\
\hline Acinetobacter spp & $100 \%$ & $0.0 \%$ & $100 \%$ & $0.0 \%$ & $100 \%$ & $100 \%$ & $100 \%$ & $0.0 \%$ & $0.0 \%$ & $100 \%$ \\
\hline Providenicaspp & $100 \%$ & $0.0 \%$ & $100 \%$ & $0.0 \%$ & $50 \%$ & $100 \%$ & $50 \%$ & $0.0 \%$ & $0.0 \%$ & $100 \%$ \\
\hline
\end{tabular}

KEY; AMP Ampicilin, CIP Ciprofloxacin, SXT Trimethoprim-sulphamethoxazole GEN Gentamycin, AMC Amoxicillin Clavulanic acid, CTR Ceftraxone, CAZ Ceftazidime, MER Meropenem, CHL Chloraphinicol, TET Tetracyclin, ND not done

infection, is known to be a risk factor for otitis media. From all children included this study, 89(58.9\%) had a URTI and 32 (20.4\%) had a throat infection. Among all study subjects, 20 (13.2\%) came from households with tobacco smokers, and 10 (6.6\%) of the patients were observed to have another person having an ear infection in their family and $57(37.5 \%)$ of them were taking antibiotics [Table 5].

\section{Association of the potential risk factors and culture positive otitis media}

Factors associated with detection of pathogenic bacteria from ear discharge in children have been analyzed but there was no statistically significant association between detection of pathogenic bacteria and most potential risk factors. However, the presence of upper respiratory tract infection showed a statistically significant relationship, with an odds ratio of 4.5 (95\% CI 1.8-12.0). Bottle feeding happened to have a negative effect on the detection of pathogenic bacteria from ear discharge, with an odds ratio of 6.5 (95\% CI 2.4-17.8) [Table 6].

\section{Discussion}

Otitis media is a major health problem in children in developing countries [12]. OM is more common in children due to the fact that children's eustachian tube is shorter, more horizontal and with a more flaccid cartilage which can easily impair its opening and leads to ear infection [4, 12]. Most cases of $\mathrm{OM}$ arise between the age of 6 month and 3 years [13].
In this study, we have been able to see the etiological agents and antimicrobial resistance pattern of isolates from children with ear infection visiting health facilities in Hawassa from April to July 2018. The overall rate of ear infection with positive culture results was $75.6 \%$, which is higher than finding in Ethiopia (48.5\%) [14] but comparable with other parts of the world including Nigeria (91\%) and Yemen $(78.0 \%)[8,15]$. The probable reasons for this could be attributed to difference in study participant, study period, climate and geographical variation.

In the present study, a similar percentage of Gram negative and Gram positive bacteria were detected (52.0 and $48.0 \%$, respectively), which is in agreement with an earlier report in Gonder (56.0 and 44.0\%) [16] .This finding was different from a study done in Hawasa (79.5\%) [17]. Possible reasons for this difference could be age group dissimilarity and study period.

The finding of this study showed that $S$. aureus was the most prevalent (27.0\%) pathogen among children having ear discharge, which was similar with the previous studies done in our country [14, 17] and abroad in Nepal $[18,19]$. However, the result was in contrast to other reports such as a study from Bahirdar Regional Health Research Laboratory Centre [16] and in other parts of the world, Pseudomonas species is the most frequently isolated organism [2]. The probable reason could be that the frequency of $S$. aureus in the middle ear infection could be attributed to their ubiquitous nature and high carriage of resistant strains in the external auditory canal and upper respiratory tract.

Table 4 Antimicrobial resistance patterns of Gram-positive bacteria isolated from ear infection among children visiting selected health facilities, Hawasa, Ethiopia, April 2018 to July

\begin{tabular}{|c|c|c|c|c|c|c|c|c|c|}
\hline Isolated organisms & CIP & GEN & SXT & PEN & CLN & $\mathrm{CHL}$ & CXT & TET & ERY \\
\hline S.aureus & $0.0 \%$ & $0.0 \%$ & $73.2 \%$ & $85.4 \%$ & $14.6 \%$ & $14.6 \%$ & $17.1 \%$ & $24.4 \%$ & $14.6 \%$ \\
\hline S.pneumonia & ND & ND & ND & ND & $0.0 \%$ & $0.0 \%$ & ND & ND & $0.0 \%$ \\
\hline Enterococcus spp. & $50 \%$ & ND & ND & 37.3 & ND & 0 & ND & $37.30 \%$ & $50.0 \%$ \\
\hline
\end{tabular}

KEY; CIP ciprofloxacin, GEN Gentamycin, SXT Trimethoprim-sulphamethoxazole, PEN Penicillin, CLN Clindamycin, CHL Chloraphenicol, CXT Cefoxitin, TET Tetracycline, ERY Erythromycin, ND not done 
Table 5 Frequency and percentage of possible risk factors for bacterial ear infection of children with ear discharge, Hawassa, SNNPR, April 2018 to July 2018

\begin{tabular}{|c|c|c|c|}
\hline Variables & & Frequency & Percent \\
\hline \multirow[t]{2}{*}{ Duration of infection } & $\begin{array}{l}\text { Less than } \\
2 \text { weeks }\end{array}$ & 100 & 65.8 \\
\hline & $\begin{array}{l}\text { More than } \\
2 \text { weeks }\end{array}$ & 52 & 34.4 \\
\hline \multirow[t]{2}{*}{ Breast feeding } & Yes & 86 & 56.6 \\
\hline & No & 66 & 43.4 \\
\hline \multirow[t]{2}{*}{ Bottle feeding } & Yes & 56 & 36.8 \\
\hline & No & 96 & 63.2 \\
\hline \multirow{2}{*}{$\begin{array}{l}\text { Presence of } \\
\text { throat infection }\end{array}$} & Yes & 31 & 20.4 \\
\hline & No & 121 & 79.6 \\
\hline \multirow{2}{*}{$\begin{array}{l}\text { Presence of tobacco } \\
\text { smoke in the house }\end{array}$} & Yes & 20 & 13.2 \\
\hline & No & 132 & 86.8 \\
\hline \multirow[t]{2}{*}{ Presence of URTI } & Yes & 89 & 58.6 \\
\hline & No & 63 & 41.4 \\
\hline \multirow{2}{*}{$\begin{array}{l}\text { Other ear infection } \\
\text { in the family }\end{array}$} & Yes & 5 & 3.2 \\
\hline & No & 147 & 96.7 \\
\hline \multirow[t]{2}{*}{ Antibiotic treatment history } & Yes & 57 & 37.5 \\
\hline & No & 95 & 62.5 \\
\hline
\end{tabular}

URTI Upper Respiratory Tract Infection
In the present study, the prevalence of Pseudomonas species was $4(2.6 \%)$. However, study conducted around the world reported Pseudomonas spp. as the most frequently isolated Gram negative pathogen from ear discharge [8]. The possible reason is that most study subjects included in this study had OM which is less than 2 weeks. Apparently, Pseudomonas species is mostly isolated from chronic OM, which is more than 2 weeks of duration or more. The other reason for this fact could be that the time or season of a year may favour some type of bacteria [15].

Our study indicates that the majority of the bacterial isolates $(65.1 \%)$ were found in children less than 5 years of age. A similar finding was also documented in some previous studies done in Gonder University Hospital, and Ayder Teaching and Referral Hospital, Mekele [9, 20]. Twelve out of $14 \mathrm{H}$. influenza isolates were identified from children less than 12 months of age. This is due to the fact that the main bacterial isolates in AOM are the same as those that typically infect the upper respiratory tract in children and $H$. influenza is known to cause URTI [20]. Out of P. mirabilis isolates, $84.2 \%$ were identified from children aged between 1 and 5 years. Similar results were reported from a study done at EPHI [14].

Table 6 Factors associated with detection of pathogenic bacteria from ear discharge among children at selected health facilities in Hawasa,Ethiopia April 2018 to July 2018

\begin{tabular}{|c|c|c|c|c|c|c|c|}
\hline \multirow[t]{2}{*}{ Characteristics } & & \multirow{2}{*}{$\begin{array}{l}\text { Number } \\
\text { tested }\end{array}$} & \multirow{2}{*}{$\begin{array}{l}\text { Culture positive } \\
N(\%)\end{array}$} & \multirow{2}{*}{$\begin{array}{l}\text { COR } \\
(95 \% \mathrm{Cl})\end{array}$} & \multirow{2}{*}{$\begin{array}{l}P \text { - } \\
\text { value }\end{array}$} & \multirow{2}{*}{$\begin{array}{l}\text { AOR } \\
(95 \% \mathrm{Cl})\end{array}$} & \multirow{2}{*}{$\begin{array}{l}P \text { - } \\
\text { value }\end{array}$} \\
\hline & & & & & & & \\
\hline \multirow[t]{2}{*}{ Sex } & Male & 78 & $59(75.6)$ & $1(0.5-2.1)$ & 0.99 & $0.54(0.2-1.5)$ & 0.19 \\
\hline & Female & 74 & $56(75.7)$ & 1 & - & 1 & - \\
\hline \multirow[t]{2}{*}{ Age group } & $\leq 5$ & 128 & $99(77.3)$ & $1.7(0.6-4.3)$ & 0.26 & $4.1(1-15.8)$ & 0.38 \\
\hline & $>5$ & 24 & $16(66.7)$ & 1 & - & 1 & - \\
\hline \multirow[t]{2}{*}{ URTI } & Yes & 89 & $74(83.1)$ & $2.6(1.2-5.6)$ & 0.012 & $4.5(1.8-12)$ & 0.001 \\
\hline & No & 63 & $41(65.1)$ & 1 & - & 1 & - \\
\hline \multirow[t]{2}{*}{ Throat infection } & Yes & 31 & $23(74.2)$ & $0.9(0.36-2.2)$ & 0.83 & $0.8(0.3-2.4)$ & 0.79 \\
\hline & No & 121 & $92(76.0)$ & 1 & - & 1 & - \\
\hline \multirow[t]{2}{*}{ Bottle feeding } & Yes & 56 & $35(62.5)$ & 1 & - & 1 & - \\
\hline & No & 96 & $80(83.3)$ & $3(1.4-6.4)$ & 0.005 & $6.5(2.4-17.8)$ & 0.000 \\
\hline \multirow[t]{2}{*}{ Breast feeding } & Yes & 86 & $64(74.4)$ & $1.1(0.55-2.5)$ & 0.68 & $0.4(0.1-1.2)$ & 0.11 \\
\hline & No & 66 & $51(77.7)$ & 1 & - & 1 & - \\
\hline \multirow[t]{2}{*}{ Duration of infection } & $\leq 15$ day & 100 & $77(77.0)$ & $0.8(0.4-1.7)$ & 0.59 & $2.0(0.8-5.1)$ & 0.11 \\
\hline & >15day & 52 & $38(73.1)$ & 1 & - & 1 & - \\
\hline \multirow[t]{2}{*}{ Residence } & Urban & 105 & $77(73.3)$ & $0.65(0.3-1.5)$ & 0.32 & $0.55(0.19-1.5)$ & 0.26 \\
\hline & Rural & 47 & $38(80.9)$ & 1 & - & 1 & - \\
\hline \multirow[t]{2}{*}{ Antibiotic treatment } & Yes & 57 & $43(75.4)$ & $0.98(0.4-2.1)$ & 0.96 & $1.4(0.6-3.4)$ & 0.42 \\
\hline & No & 95 & $72(75.8)$ & 1 & - & 1 & - \\
\hline
\end{tabular}


In this study, lower resistance was observed to ciprofloxacin (7.3\%) and gentamicin (11.2\%), though resistance rates were high to ampicilin (85.2\%), trimethoprim-sulphamethoxazole (72.0\%)and penicillin (71.4\%), which was consistent with several reports elsewhere [4, 8, 16, 18]. Klebsiella species are known for their resistance to several drugs [10], and a similar finding was also observed in the current study. $S$. aureus showed higher resistance for penicillin and trimethoprim-sulphamethoxazole with 85.4 and $73.2 \%$, respectively. This is comparable with the study done in Jimma, where $84 \%$ of $S$. aureus isolates were found to be resistant to penicillin [19] . Even though gentamicin is a parenteral drug and ciprofloxacin is rarely used in children due to concerns of bone/joint effects, these two drugs were highly effective antibiotics and thus should be considered in treating children with otitis media since most organisms were resistance or poor response to first line drugs. Gentamicin should not be used as mono-therapy for S. aureus infections. Indeed, there is little evidence it has any utility in any $S$. aureus infections. S. aureus showed no resistance to ciprofloxacin and gentamicin which is in agreement with studies done in Jimma and Bahirdar [16, 19]. The probable reasons for this variation could be attributed to antimicrobial resistance profile of bacteria varies among population because of difference in geography, local antimicrobial prescribing practices and prevalence of resistant bacterial strains.

Factors associated with detection of pathogenic bacteria from ear discharge in children have been analyzed but there was no statistically significant association between detection of pathogenic bacteria and most of the potential risk factors. However, presence of upper respiratory tract infection showed a statistically significant relation, with an AOR of 4.5 (95\% CI 1.8-2.0). This was in agreement with the result in Jimma [19]. It is also known that upper respiratory tract infections are one of the major reasons for impaired middle ear physiology [13].

\section{Conclusion}

Otitis media is still a major health problem of children and bacterial agents are the main cause. The most commonly isolated bacterial pathogen from ear discharge among children is $S$. aureus followed by $P$. mirabilis. There was a high level of antibiotic resistance observed among isolates of ear discharge from children. Ampicilin, penicillin and trimethoprim-sulphamethoxazole were less effective against the isolates. Apparently, ciprofloxacin, gentamicin and chloraphinecol showed good effect against most bacterial pathogens that cause OM. Drug resistant strains of $S$. aureus such as MRSA and MSLBi can cause ear infection. Upper respiratory tract infection is a risk factor for ear infection among children.

\section{Abbreviations}

AOM: Acute Otitis Media; BAP: Blood Agar Plate; CAP: Chocolate Agar Plate; CLSI: Clinical and Laboratory Standards Institute; CSOM: Chronic Suppurative Otitis Media; EPHI: Ethiopian Public Health Institute; HUCSH: Hawassa University Comprehensive Specialized Hospital; MAC: Macckonkey Agar; MDR: Multi Drug Resistance; OM: Otitis Media; OME: Otitis Media with Effusion; PBP: Penicillin Binding Protein; SNNPR: Southern Nations Nationalities People Region; URTI: Upper Respiratory Tract Infection; WHO: World Health Organization

\section{Acknowledgments \\ We would like to thank HUCSH, Ear Nose and throat (ENT) clinic nurses, especially Sister Nigisti Kebede and Sister Simegn Asmare, for helping me during data collection. We acknowledge the Microbiology Laboratory staff at HUCSH, Mr. Enkusilasie Mitiku, Mr. Tsegaye Alemayew w/o Elshaday Azerefegn and W/o Netsanet Nigusie helped me during my data collection and sample processing. We would also give my acknowledgment for Dr. Nigus Chanie who is a paediatrician at Rama Paediatric Clinic for his support during sample collection.}

\section{Authors' contributions}

BT conceived and designed the study, performed analysis, Interpretation of data, and drafts the manuscript. TS and MW assisted with the design, performed analysis, interpretation of data and the critical review of the manuscript. All authors read and approved the final manuscript. All authors participated in critical appraisal and revision of the manuscript.

\section{Funding}

No fund.

\section{Availability of data and materials}

If someone wants to request the data, it is available on hand of Bereket Tadesse.

\section{Ethics approval and consent to participate}

Ethical clearance was obtained after review and approval of the proposal by the Institutional Review Board (IRB) of Hawassa University College of Medicine and Health Science. Then support letters were obtained from the School of Medical Laboratory Science and concerned health facilities administration. Each study parent/guardian was informed about the objective study and all information contained within the questionnaire is to be kept confidential. Moreover, he/she has been well informed of his/her right to refuse information, decline to cooperate and drop out of the study if he/she want and none of his/her actions will have any bearing at all on child overall health care. Therefore, with full understanding of the situations, the agreed parents/guardians were put their signature on written consent form. Data was collected after the parents/guardians gave written consent.

Consent for publication

Not applicable.

Competing interests

The authors declare that they have no competing interests.

\section{Author details}

${ }^{1}$ Hawassa University College of Medicine and Health Science, Comprehensive Specialized Laboratory, Hawassa, Ethiopia. ${ }^{2}$ Hawassa University College of Medicine and Health Science, Hawassa, Ethiopia. ${ }^{3}$ College of Medicine and Health Science, School of Medical Laboratory, Hawassa university, Hawassa, Ethiopia.

Received: 15 February 2019 Accepted: 10 October 2019

Published online: 01 November 2019

\section{References}

1. Woodfield G, Dugdale A. Evidence behind the WHO guidelines: hospital care for children: what is the most effective antibiotic regime for chronic suppurative otitis media in children? J Trop Pediatr. 2008;54(3):151-6.

2. Appiah-Korang L, Asare-Gyasi S, Yawson A, Searyoh K. Aetiological agents of ear discharge: a two year review in a teaching hospital in Ghana. Ghana Med J. 2014;48(2):91-5. 
3. Akinpelu O, Amusa Y, Komolafe E, Adeolu A, Oladele A, Ameye S. Challenges in management of chronic suppurative otitis media in a developing country. J Laryngol Otol. 2008;122(1):16-20.

4. Hechukwu GC, llechukwu CA, Ubesie AC, Okoroafor I, Ezeanolue BC, Ojinnaka NC. Bacterial agents of the discharging middle ear among children seen at the University of Nigeria Teaching Hospital, Enugu. Pan Afr Med J. 2017;26.

5. Roberts JE, Zeisel SA. Ear infections and language development; 2000.

6. Ahmad S. Antibiotics in chronic suppurative otitis media: a bacteriologic study. Egypt J Ear Nose Throat Allied Sci. 2013;14(3):191-4.

7. Levy SB. Factors impacting on the problem of antibiotic resistance. J Antimicrob Chemother. 2002:49(1):25-30.

8. Mohammed S, Al-Kadassy A, Bashanfer S, Moad Al. Bacterial isolates from otitis media infections and their Antibiograms, Hodeidah City, Yemen. Brit Microbiol Res J. 2016;13(1):1.

9. Muluye $D$, Wondimeneh $Y$, Ferede G, Moges F, Nega T. Bacterial isolates and drug susceptibility patterns of ear discharge from patients with ear infection at Gondar University Hospital, Northwest Ethiopia. BMC Ear Nose Throat Disord. 2013;13(1):10.

10. Cheesbrough M. Biochemical tests to identify bacteria. In: District Laboratory Practice in Tropical Countries (Part 2). Low priced ed. Cambridge: Cambridge University Press; 2002. p. 62-70.

11. Clinical, Institute LS: Performance standards for antimicrobial susceptibility testing of anaerobic bacteria: informational supplement: Clinical and Laboratory Standards Institute (CLSI); 2009.

12. Idowu A, Oluremi B, Seidu N. Incidence and susceptibility pattern of clinical isolates from pus producing infection to antibiotics and Carica papaya seed extract. Afr J Biotechnol. 2011;10(9):1700-4.

13. Lieberthal AS, Carroll AE, Chonmaitree T, Ganiats TG, Hoberman A, Jackson MA, Joffe MD, Miller DT, Rosenfeld RM, Sevilla XD. The diagnosis and management of acute otitis media. Pediatrics. 2013;131(3):e964-99.

14. Hailegiyorgis TT, Sarhie WD, Workie HM. Isolation and antimicrobial drug susceptibility pattern of bacterial pathogens from pediatric patients with otitis media in selected health institutions, Addis Ababa, Ethiopia: a prospective cross-sectional study. BMC Ear Nose Throat Disord. 2018;18(1):8.

15. Ogbogu Pl, Eghafona NO, Ogbogu Ml. Microbiology of otitis media among children attending a tertiary hospital in Benin City, Nigeria. J Public Health Epidemiol. 2013;5(7):280-4.

16. Hailu D, Mekonnen D, Derbie A, Mulu W, Abera B. Pathogenic bacteria profile and antimicrobial susceptibility patterns of ear infection at Bahir Dar regional Health Research Laboratory center, Ethiopia. SpringerPlus. 2016;5(1):466.

17. Worku M, Bekele M. Bacterial isolate and antibacterial resistance pattern of ear infection among patients attending at Hawassa university referral hospital, Hawassa, Ethiopia. Indian J Otol. 2014;20(4):155.

18. Shrestha B, Amatya R, Shrestha I, Ghosh I. Microbiological profile of chronic supurative otitis media. Nepalese J ENT Head Neck Surg. 2011;2(2):6-7.

19. Muleta D, Gebre-Selassie S. Isolation and antimicrobial susceptibility patterns of bacterial pathogens causing otitis media in children in Jimma Hospital, Southwestern Ethiopia. Ethiop J Health Sci. 2004;14(2).

20. Wasihun AG, Zemene Y. Bacterial profile and antimicrobial susceptibility patterns of otitis media in Ayder teaching and referral hospital, Mekelle University, Northern Ethiopia. SpringerPlus. 2015;4(1):701.

\section{Publisher's Note}

Springer Nature remains neutral with regard to jurisdictional claims in published maps and institutional affiliations.

\section{Ready to submit your research? Choose BMC and benefit from:}

- fast, convenient online submission

- thorough peer review by experienced researchers in your field

- rapid publication on acceptance

- support for research data, including large and complex data types

- gold Open Access which fosters wider collaboration and increased citations

- maximum visibility for your research: over $100 \mathrm{M}$ website views per year

At $\mathrm{BMC}$, research is always in progress.

Learn more biomedcentral.com/submissions 